\title{
Sulfonylureas Induced Hypoglycemia in Diabetics - A Review
}

\author{
Adegbenga Bolanle Ademolu \\ Medicine Department, Lagos State University Teaching Hospital, Ikeja, Lagos, Nigeria \\ Email address: \\ ademoluab@yahoo.com \\ To cite this article: \\ Adegbenga Bolanle Ademolu. Sulfonylureas Induced Hypoglycemia in Diabetics - A Review. International Journal of Diabetes and \\ Endocrinology. Special Issue: Hypoglycemia in Diabetes. Vol. 4, No. 4, 2019, pp. 108-112. doi: 10.11648/j.ijde.20190404.14
}

Received: November 14, 2019; Accepted: November 26, 2019; Published: December 4, 2019

\begin{abstract}
Diabetes is a metabolic disorder of glucose characterized by glucotoxicity, lipotoxicity and insulin resistance. In insulin resistance states, a higher level of insulin is needed to generate the usual body response to keep plasma glucose at physiologic level. The type 2 diabetics with insulin resistance cannot keep plasma glucose normal not because of absolute insulin deficiency but due to a relative deficiency as insulin is now required at a higher plasma level to achieve a near physiological or physiological plasma glucose level. Hence the need for a chemical agent to increase insulin secretion from the pancreatic beta cells at pharmacological dose (insulin secretagogues) was conceptualized and arrived at. Sulfonylureas are insulin secretagogues. Two generations of sulfonylurea's are in use. The first and second. The class effects of sulfonylurea include weight gain, allergic reaction and hypoglycemia. But not enough emphasis is placed on the severity and grading of the hypoglycemia complicating use of sulfonylureas. Meanwhile hypoglycemia induced by sulfonylurea use is of various degree, severity and duration. The classification of hypoglycemia into grades in ADEMOLUS CLASSIFICATION OF HYPOGLYCEMIA makes it easier for scientist to understand, compare and monitor the severity of sulfonylureas. Mrs KFO is a 67 years old diabetic diagnosed over 8 years ago. She had asymptomatic hypoglycemia with a glucometer reading low (ADEMOLUS PHENOMENON) on a clinic day visit. She had been on glimepiride for three years. Mrs A. F. is a 75 years old diabetic diagnosed 4 years prior to presentation. She had a glucometer reading of low during a random blood sugar check at 8pm on day 2 of admission with associated general body weakness. She was on metformin and glibenclamide. Mrs. I E is a 72 years old diabetic who had a glucometer reading of low during her outpatient clinic visit. She was on gliclazide. Sulfonylureas use has been shown by these cases to be associated with symptomatic and asymptomatic very severe hypoglycemia. A possibility of synthesizing a new equally potent third generation of sulfonylureas with minimal or no hypoglycemic effect should be looked into.
\end{abstract}

Keywords: Sulfonylureas, Hypoglycemia, Diabetes Mellitus

\section{Introduction}

The metabolism of glucose in the internal milieu plays a vital role in the survival of cells in vivo in the life of mankind. Both the anabolic and catabolic processes involved in glucose metabolism in physiologic states gives a homeostatic state of euglycemia or normoglycemia in the physiologic 70kg man [1-3].

Several disorder of these processes have been described in literature in man some due to storage diseases while others are due to metabolic disorders occasioned by genetic, autoimmune or infective conditions or drug use [4-6].

A metabolic disorder of glucose metabolism favoring anabolism than catabolism with a resultant chronic hyperglycemia is generally known as diabetes mellitus. The chronic hyperglycemia of diabetes result in prolonged exposure of virtually all cells in human body to persistently high levels of glucose which is toxic to the normal molecular processes of the human body. This glucotoxicity [7-8] is injurious and is one of the pathophysiological processes that are addressed in people living with diabetes mellitus apart from lipotoxicity [9].

Insulin resistance [10-11] is a major pathological mechanism in type 2 diabetes mellitus that favors chronic hyperglycemia. The threshold for peripheral uptake of glucose is increased in individuals with insulin resistance. In insulin resistance states, a higher level of insulin is needed to generate the usual body response to keep plasma glucose at 
physiologic levels. The type 2 diabetics with insulin resistance cannot keep plasma glucose normal not because of absolute insulin deficiency but due to a relative deficiency as insulin is now required at a higher plasma level to achieve a near physiological or physiological plasma glucose level. Hence the need for a chemical agent to increase insulin secretion from the pancreatic beta cells at pharmacological dose was conceptualized and arrived at. These drugs because they stimulate production of insulin from the pancreatic beta cells are known as insulin secretagogues. They can be sulfonylureas or meglitinides (Repaglinide and Nateglinides). In this review, attention will be focused on sulfonylureas.

\section{Sulfonylureas}

In 1942 Janbon et al observed that some sulphonamides generated hypoglycemia in his translational study. Based on this, carbutamide (1-butyl-3-sulfonyureas) was synthesized as the first sulfonylurea used to treat diabetes but was later withdrawn from the market due to its adverse effect on bone marrow [12]. In the 1950s other sulfonylureas were released to the market for treatment of diabetes.

In our contemporary times two generations of sulfonylureas are in use. The first generation consist of Acetohexamide, Chlorpropamide, Tolazamide, Tolbutamide. The second generation consist of Glipizide, Glimepiride, Glyburide, Gliclazide, Gliquidone.

Sulfonylureas act at the pancreatic $\beta$-cell membrane by closing ATP-sensitive potassium channels, which leads to an enhanced insulin secretion independent of glucose [13].

The class effects of sulfonylurea includes weight gain, hypoglycemia and allergic reaction in first few weeks 6 to 8 week of usage in some individuals.

Acetohexamide has been associated with increased cardiovascular mortality. Chlorpropamide is associated with greater number of side effects in the geriatric and renal impairment, it can cause agranulocytosis and aplastic anemia. Tolazamide can cause dizziness and vertigo and rarely cholestatic jaundice. Tolbutamide can cause hyponatreamia and thrombocytopenia [14-15].

The second generation sulfonylureas glipizide can cause urticaria, syncope and abdominal pain, glimepiride can cause asthenia, agranulocytosis, anemia and aplastic anemia. Glyburide (also called glibenclamide) can cause myalgia, arhralgia, hyponatreamia, angioedema and vasculitis. Gliclazide causes heartburn and diarrhea and lethargy. Gliquidone is fully metabolized in the liver and is useful in patients with diabetic nephropathy, its side effects includes syndrome of inappropriate anti diuretic hormone secretion, gastrointestinal disturbance, Steven Johnson syndrome. erythema nodosum and exfoliative dermatitis [14-16].

\section{Hypoglycemia as Side Effects of Sulfonylureas}

Hypoglycemia complicating sulfonylureas use is well documented in literature [17-18]. But not enough emphasis is placed on the severity and grading of the hypoglycemia. Meanwhile hypoglycemia induced by sulfonylurea use is of various degree, severity and duration [19-21].

The classification of hypoglycemia into grades in ADEMOLUS CLASSIFICATION OF HYPOGLYCEMIA [22-24] makes it easier for scientist to understand, compare and monitor the severity of hypoglycemia caused by each member of the sulfonylureas group of oral hypoglycemic agents that are still in clinical use.

To illustrate this usefulness of ADEMOLUS CLASSIFICATION OF HYPOGLYCEMIA (ACH) in patients on sulfonylureas, I am going to cite some clinical cases I encountered in the third and fourth quarter of 2019 in my practice.

\subsection{Case 1}

Mrs. KFO is a 67 years old woman living with type 2 diabetes mellitus diagnosed more than 8 years ago. She usually do not have hypoglycemia however on this particular clinic day, her home fasting blood sugar measured at $6.30 \mathrm{am}$ was $168 \mathrm{mg} / \mathrm{dl}$. At $8.30 \mathrm{am}$, the nursing staff did her hospital based fasting blood sugar which had a glucometer reading of low! (that is less than $10 \mathrm{mg} / \mathrm{dl}$ ) She was asked by nursing staff to go and eat and random blood sugar check one hour post prandial was $179 \mathrm{mg} / \mathrm{dl}$. During consultation she reported no symptom during the period she had the low reading on glucometer and personally expressed surprise that she was asymptomatic at such dangerously low blood sugar level.

Her usual medication are vildagliptin/metformin 50/1000 (Galvusmet), glimepiride $4 \mathrm{mg}$ daily, Atorvastatin $20 \mathrm{mg}$ daily and tab Pregabalin $75 \mathrm{mg}$ daily, Mrs. KFO possibly had hypoglycemia unawareness [25] at a dangerously low blood sugar level. Her stating that she don't usually have hypoglycemia suggest that many of such hypoglycemic episodes would have gone unnoticed by her and got corrected unknowingly with meal! Her being on glimepiride chronically makes her to be at risk of exposure to chronic low blood sugar [25]. Her long standing diabetes mellitus also is in keeping with the possibility of hypoglycemia unawareness in her from autonomic dysfunction complicating her diabetes.

Drug to drug interaction between glimepiride and atorvastatin cannot be cited as cause of this very low hypoglycemia in her as such drug interaction is not documented in literature. Her continuous use of glimepiride $4 \mathrm{mg}$ for three consecutive years translates to the fact that she had a sustained serum level of glimepiride in her blood that her internal milieu had become used to. The effects of this chronic use on molecular function needs to be looked into in such patients.

Her case suggest that more research need to go into evaluating mean blood glucose level in subjects with chronic use of glimepiride for three years or more, that is the effect of long term use of glimepiride on glucose homeostasis and the rapidity of glimepiride induced hypoglycemia during chronic use and acute use in an hyperglycemic patient need to be 
looked into! Does it have anything to do with sulfonylureas receptor upregulation or downregulation? The other drugs she is on metformin and vildagliptin are not associated (metformin) or are rarely associated (vildagliptin) with hypoglycemia.

Her case is the first case of ADEMOLUS PHENOMENON [22-24] I will be encountering in a diabetic patient! That is asymptomatic hypoglycemia at blood glucose level less than $10 \mathrm{mg} / \mathrm{dl}$ in a diabetes mellitus patient! It is interesting too that this is been described for the first time in an elderly diabetic patient on chronic use of glimepiride for 3 years! She had grade 4 hypoglycemia (ADEMOLUS PHENOMENON) as an outpatient individual living with diabetes mellitus.

\subsection{Case 2}

Mrs. A. F. is a 75 years old retired civil servants diagnosed with diabetes mellitus 4 years prior to presentation. She was referred from a private hospital with a history of low grade fever, recurrent bilateral leg swelling, intermittent claudication and left foot ulcer of five weeks duration with visual blurring, her random blood sugar from referring hospital was $40 \mathrm{mg} / \mathrm{dl}$ (grade 2 hypoglycemia) and white cells count was $18,400 \times 10^{6} / \mathrm{mm}^{3}$. She was on tab metformin 1 gram tds (an overdosage especially in an elderly) and glibenclamide $10 \mathrm{mg}$.

She was not on medication until four weeks before presentation when she started the metformin and glibenclamide. On admission her random blood sugar was $92 \mathrm{mg} / \mathrm{dl}$. She was admitted as a case of left diabetes foot syndrome and diabetic nephropathy.

Second day on admission, she had a glucometer reading of low during a random blood sugar check at $8 \mathrm{pm}$. She drank half bottle of a carbohydrate drink (coca cola) after which her random blood sugar became $205 \mathrm{mg} / \mathrm{dl}$ thirty minutes later she had not started insulin since admission but was on her metformin and glibenclamide. When she had the low random blood sugar prior to taking glucose drink, she had general body weakness and fever; she could not sit up in bed but was not fully unconscious as she was aware of resuscitative measures carried out on her by the attending medical staff.

Her case clearly demonstrates a case of symptomatic grade 4 hypoglycemia in a diabetic patient that is a symptomatic very severe hypoglycemia in a diabetic elderly patient on metformin and glibenclamide.

It is worth nothing that she was on a dosage of metformin that is above the pharmacologically accepted maximum dosage for her especially been an elderly with a reduced glomerular filtration rate. An accumulation of her metformin may predispose her to lactic acidosis. Her glibenclamide is the most likely cause of her grade 4 hypoglycemia here especially in the presence of overdosage of another oral hypoglycemic agent. It will be interesting to study the effects of overdosage of other oral hypoglycemic agent in patients on sulfonylureas especially in relation to development of hypoglycemia in animal models. The reason is because in practice some patient takes overdosage of these drugs unknowingly or are given overdosage from non qualified persons. In her case a nurse (may be an auxiliary nurse) placed this patient of 75 years of age on 3 grams of metformin in a day!

\subsection{Case 3}

Mrs. I E is a 72 years old lady who had a glucometer reading of low during her visit to the rheumatology clinic of our hospital for her routine follow up for bilateral osteoarthritis. She had had intra-articular injection in the past and is being scheduled for another session. She was asked to go and eat by the nursing staff after her glucometer read low.

She walked 200 meters to the food vendor in the hospital where she ate and walked back to the clinic for her scheduled rheumatology consultation for the day! Her post prandial glucose was not checked by the nursing staff.

After her consultation she went home and presented four days later for her scheduled endocrinology clinic follow up. A look at her previous record four days earlier revealed these occurrences described above which was confirmed by the nursing staff that attended to her four days earlier. She had ADEMOLUS PHENOMENON four days earlier at the rheumatology clinic! She had asymptomatic hypoglycemia at a reading less than $10 \mathrm{mg} / \mathrm{dl}$.

Her dietary lifestyle revealed she takes a lot of vegetables in her diet (vegetables is rich in vitamin B6-pyridoxal phosphate which helps prevents the brain from injury in the presence of very low blood sugar). It has been suggest that pyridoxal phosphate protects neurons from glucose deprivation- induced damage by enhancing the formation of energy-yielding products and relieving extracellular load of glutamate. The observed phenomena further indicate that pyridoxal phosphate might be used prophylactically against neuronal death induced by metabolic disorders [22]. This may be the biochemical explanation for her being stable in the face of dangerously low blood sugar level four days earlier. She also revealed that she takes wheat bread occasionally (enriched wheat flour may be a good source of iron, thiamine, niacin, calcium, and vitamin B6-pyridoxal phosphate) [26].

On the review day in the endocrinology clinic, her fasting blood sugar was $103 \mathrm{mg} / \mathrm{dl}$ her pulse was 78 beats/min her blood pressure was $135 / 80 \mathrm{mmHg}$. She walked into consulting room unaccompanied. Her usual drug was gliclazide $60 \mathrm{mg}$ daily for the past five months prior to review; she was on glibenclamide $2.5 \mathrm{mg}$ daily before been switched to gliclazide. Her other drugs include metformin $500 \mathrm{mg}$ bd, pregabalin $75 \mathrm{mg}$ daily and tizanidine $4 \mathrm{mg}$ daily. She used her sulfonylureas gliclazide a day before her sugar recorded low in the rheumatology clinic. She had been diabetic for ten years and had had only one episode of hypoglycemia of $61 \mathrm{mg} / \mathrm{dl}$ (grade 1 hypoglycemia) which occurred in 2014.

This is another case of ADEMOLUS PHENOMENON in a diabetic patient! Her walking for 200 meters after low random blood sugar (less than $10 \mathrm{mg} / \mathrm{dl}$ ) is possibly because her brain had adjusted well to chronic hypoglycemia over 
time since she had chronically been on sulfonylureas initially glibenclamide and lately gliclazide.

\subsection{Case 4}

Mrs. S. D. is 59 years old known diabetic for 7 years. On a clinic visit when asked whether she had had hypoglycemia in the past, she reported that some years back she checked her blood sugar at home and it read low! She did not have any symptom so she quickly took milk, milo (a beverage drink) and ate. She did not check her blood sugar thereafter. Her fasting blood sugar was normal the next day but could not remember exact value. She was on oral hypoglycemic agents but could not remember which as it was years past.

This is a domiciliary case of ADEMOLUS PHENOMENON that occurred years back. She had ADEMOLUS PHENOMENON at home from her experience. Though in her case it could not be ascertained if sulfonylureas are part of her oral hypoglycemic agent medication at that time. But this is not impossible since sulfonylureas are cheap, easily prescribed and notorious for causing hypoglycemia.

Sulfonylureas use has been shown by these cases especially the first three cases to be associated with very severe hypoglycemia which can be symptomatic or asymptomatic. It is worth noting that the asymptomatic very severe hypoglycemia (ADEMOLUS PHENOMENON) before now is rarely reported by clinicians in literature meanwhile this does not stop patients experiencing it when it occurs, a low level of awareness may be responsible for this and a high index of suspicion is what is needed to detect it.

The concept that sulfonylureas cause hypoglycemia as a class effect is well reported in literature [27-29]. However this review article adds the additional point that the hypoglycemia caused can be very severe and in the very severe state, it can be symptomatic or asymptomatic hypoglycemia as depicted by glimepiride induced hypoglycemia, glibenclamide induced hypoglycemia and gliclazide induced hypoglycemia cited in this review.

This understanding have to be imbibed by fellow clinicians, scientists and researchers in order to move medical and clinical practice involving sulfonylureas induced hypoglycemia to the next level of scientific understanding and breakthrough. This will improve healthcare delivery to the benefit of diabetics on sulfonylureas to the next level.

Recently the United States Food and Drug Administration approved nasal glucagon spray for the treatment of severe hypoglycemia [30-31]. This is good as it will be helpful in treating asymptomatic severe hypoglycemia when detected without a third person assistance.

With the cases discussed in this review article it is expected that the knowledge base of scientist, diabetologist, endocrinologist on hypoglycemia especially in diabetics will now change for the better as earlier stated in my article five years ago [22] that ADEMOLUS CLASSIFICATION OF HYPOGLYCEMIA has the tendency to change the scientific world for the better.

\section{Future Direction}

A possibility of synthesizing a new equally potent third generation of sulfonylureas with minimal or no hypoglycemic effect should be looked into. All pharmacological sulfonylureas contain a central $S$-arylsulfonylurea structure with a $p$-substituent on the phenyl ring $(\mathrm{R})$ and various groups terminating the urea $N^{\prime}$ end group $\left(\mathrm{R}^{1}\right)$. See figure 1. A look into this chemical structures of sulfonylureas with aim of changing the sequence and/or chemical bonding of the elements in the structure that are associated with hypoglycemia with aim of reducing hypoglycemic effect to the bearest minimum in the new generation sulfonylureas should be sort.

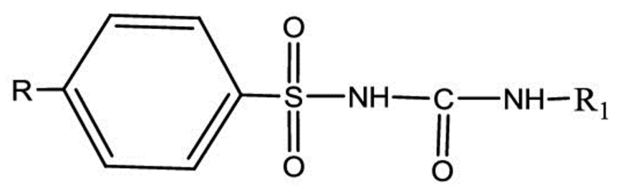

Figure 1. General chemical structure of sulfonylureas.

\section{Conclusion}

Sulfonylureas have remained relevant in the management of type 2 diabetes mellitus despite the recent advances in therapeutic measures in diabetes mellitus management. Hypoglycemia complicating use of sulfonylureas can be of varying degree of severity and can be symptomatic or asymptomatic. Attempt has to be made to develop an improved equally potent third generation of sulfonylureas with minimal or no hypoglycemic side effects.

\section{References}

[1] Carey M, Kehlenbrink S. Hawkins M. Evidence for central regulation of glucose metabolism. J Biol Chem. 2013 Dec 6; 288 (49): 34981-8.

[2] Petersen MC, Vatner DF, Shulman GI. Regulation of hepatic glucose metabolism in health and disease. Nat Rev Endocrinol. 2017 Oct; 13 (10): 572-587.

[3] Stephen L. Aronoff, Kathy Berkowitz, Barb Shreiner, and Laura Want. Glucose Metabolism and Regulation: Beyond Insulin and Glucagon. Diabetes Spectrum 2004 Jul; 17 (3): 183-190.

[4] Bulcun E, Ekici M. Ekici A. Disorders of glucose metabolism and insulin resistance in patients with obstructive sleep apnoea syndrome. Int J Clin Pract. 2012 Jan; 66 (1): 91-7.

[5] Dubé MP. Disorders of glucose metabolism in patients infected with human immunodeficiency virus. Clin Infect Dis. 2000 Dec; 31 (6): 1467-75. Epub 2000 Nov 29.

[6] Chou JY, Jun HS, Mansfield BC. Type I glycogen storage diseases: disorders of the glucose-6-phosphatase/glucose-6phosphate transporter complexes. J Inherit Metab Dis. 2015 May; 38 (3): 511-9.

[7] Kaiser N, Leibowitz G, Nesher R. Glucotoxicity and beta-cell failure in type 2 diabetes mellitus. J Pediatr Endocrinol Metab. 2003 Jan; 16 (1): 5-22. 
[8] Shinji Kawahito, Hiroshi Kitahata, and Shuzo Oshita. Problems associated with glucose toxicity: Role of hyperglycemia-induced oxidative stress. World J Gastroenterol. 2009 Sep 7; 15 (33): 4137-4142.

[9] Del Prato S.. Role of glucotoxicity and lipotoxicity in the pathophysiology of Type 2 diabetes mellitus and emerging treatment strategies. Diabet Med. 2009 Dec; 26 (12): 118592.

[10] Gisela Wilcox. Insulin and Insulin Resistance. Clin Biochem Rev. 2005 May; 26 (2): 19-39.

[11] Andrew M. Freeman; Kristina Soman-Faulkner; Nicholas Pennings. Insulin Resistance. May 10, 2019.

[12] Daniele Sola, Luca Rossi, Gian Piero Carnevale Schianca, Pamela Maffioli, Marcello Bigliocca, Roberto Mella, Francesca Corlianò, Gian Paolo Fra, Ettore Bartoli, and Giuseppe Derosa. Sulfonylureas and their use in clinical practice. Arch Med Sci. 2015 Aug 12; 11 (4): 840-848.

[13] Ryan A. Costello; Abhijit Shivkumar. Sulfonylureas. Last Update: September 24, 2019.

[14] Rendell M. The role of sulphonylureas in the management of type 2 diabetes mellitus. Drugs. 2004; 64 (12): 1339-58.

[15] Sanjay Kalra, Silver Bahendeka, Rakesh Sahay, Sujoy Ghosh, Fariduddin Md, Abbas Orabi et al. Consensus Recommendations on Sulfonylurea and Sulfonylurea Combinations in the Management of Type 2 Diabetes Mellitus - International Task Force. Indian J Endocrinol Metab. 2018 Jan-Feb; 22 (1): 132-157.

[16] Antonios Douros, Hui Yin, Oriana Hoi Yun Yu, Kristian B. Filion, Laurent Azoulay and Samy Suissa. Pharmacologic Differences of Sulfonylureas and the Risk of Adverse Cardiovascular and Hypoglycemic Events. Diabetes Care 2017 Nov; 40 (11): 1506-1513.

[17] Oriana Yu, Laurent Azoulay, Hui Yin, Kristian B. Filion, Samy Suissa. Sulfonylureas as Initial Treatment for Type 2 Diabetes and the Risk of Severe Hypoglycemia. The American Journal of Medicine. March 2018 Volume 131, Issue 3, Pages 317.

[18] Judith van Dalem, Martijn C G J Brouwers, Coen D A Stehouwer, André Krings, Hubert G M Leufkens, Johanna H M Driessen, Frank de Vries, Andrea M Burden. Risk of hypoglycaemia in users of sulphonylureas compared with metformin in relation to renal function and sulphonylurea metabolite group: population based cohort study $B M J$ 2016; 354: $i 3625$.

[19] Schloot NC, Haupt A, Schütt M, Badenhoop K, Laimer M, Nicolay C, Reaney M et al. Risk of severe hypoglycemia in sulfonylurea-treated patients from diabetes centers in
Germany/Austria: How big is the problem? Which patients are at risk? Diabetes Metab Res Rev. 2016 Mar; 32 (3): 316-24.

[20] Won Chul Ha, Su Jin Oh, Ji Hyun Kim, Jung Min Lee, Sang Ah Chang, Tae Seo Sohn et $\backslash$ al. Severe Hypoglycemia Is a Serious Complication and Becoming an Economic \Burden \ in Diabetes. Diabetes Metab J. 2012 Aug; 36 (4): 280-284.

[21] Nicola N. Zammitt, and Brian M. Frier. Hypoglycemia in Type 2 Diabetes Pathophysiology, frequency, and effects of different treatment modalities. Diabetes Care 2005 Dec; 28 (12): 2948-2961.

[22] Ademolu AB, Ademolu AO, Ogbera AO, Fasanmade OA. (2015) Hypoglycemia in lkorodu. Journal of Asian Health.

[23] Ademolu AB (2017) Role of Ademolus Classification of Hypoglycemia in Blood Glucose and Diabetes Mellitus Management. Gastroenterol Liver Clin Med (2017) 1: 1003.

[24] Adegbenga B Ademolu (2019) Analysis of Hypoglycemic Episodes in Diabetics in Africans Using Ademolus Classification of Hypoglycemia (ACH). Acta Scientific Medical Sciences 3 (3): 138-145.

[25] Iciar Martín-Timón and Francisco Javier del Cañizo-Gómez. Mechanisms of hypoglycemia unawareness and implications in diabetic patients. World J Diabetes. 2015 Jul 10; 6 (7): 912 926.

[26] Peter R. Shewry and Sandra J. Hey. The contribution of wheat to human diet and health. Food Energy Secur. 2015 Oct; 4 (3): 178-202.

[27] Clemens KK, McArthur E, Dixon SN, Fleet JL, Hramiak I, Garg AX. The Hypoglycemic Risk of Glyburide (Glibenclamide) Compared with Modified-Release Gliclazide. Can J Diabetes. 2015 Aug; 39 (4): 308-16.

[28] Bo Ahrén, James Edward Foley, Sylvie Dejager, Mouna Akacha, Qing Shao, Guenter Heimann, Markus Dworak, and Anja Schweizer. Higher Risk of Hypoglycemia with Glimepiride Versus Vildagliptin in Patients with Type 2 Diabetes is not Driven by High Doses of Glimepiride: Divergent Patient Susceptibilities? Diabetes Ther. 2014 Dec; 5 (2): 459-469.

[29] Arshad Hussain, Iftikhar Ali, Aziz Ullah Khan, and Tahir Mehmood Khan. Glibenclamide-induced profound hypoglycaemic crisis: a case report. Ther Adv Endocrinol Metab. 2016 Apr; 7 (2): 84-87.

[30] FDA approves first treatment for severe hypoglycemia that can be administered without an injection. July 24, 2019.

[31] Pilar I Beato-Víbora, and Francisco J Arroyo-Díez, New uses and formulations of glucagon for hypoglycaemia. Drugs Context. 2019; 8: 212599. 